\title{
Journal of Failure Analysis and Prevention Best Paper Award Presented at MS\&T '13
}

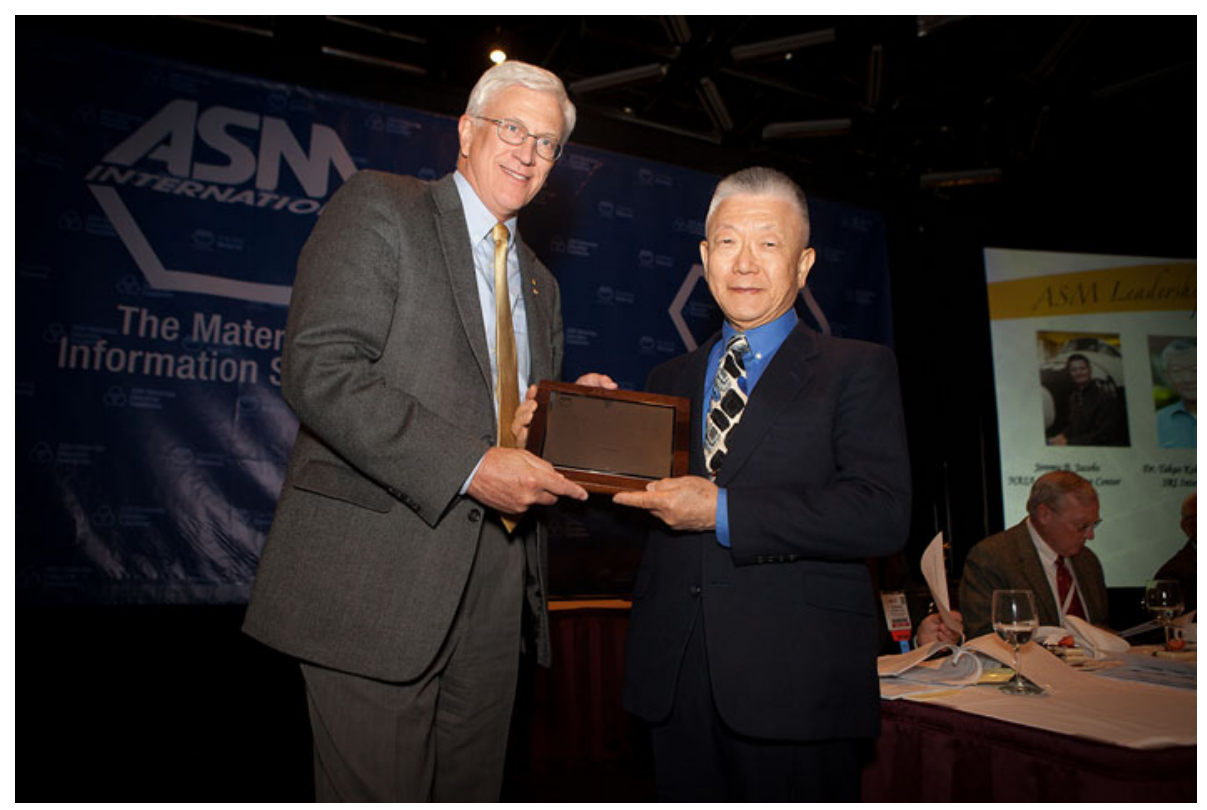

Dr. Gernant E. Maurer, President, ASM International (left), presents the Volume 12 JFAP Best Paper Award Plaque to Dr. Takao Kobayashi (right) during MS\&T '13

Dr. Michael E. Stevenson, editor of the Journal of Failure Analysis and Prevention (JFAP), announced that the JFAP Volume 12 Best Paper is "Replaying the Fracture Process of a Failed Space Shuttle Orbiter Thruster" by Dr. Takao Kobayashi, Dr. Donald. A. Shockey, and Mr. Jeremy Jacobs. The winning article was published in the December 2012 issue of JFAP.
The JFAP Volume 12 Best Paper Award was presented during the 2013 Leadership Awards Luncheon at MS\&T ' 13 in Montreal, Canada, on October 28, 2013.

The award, in addition to the recognition, includes a plaque and $\$ 1000$ worth of ASM International products and services. The Best Paper was selected by the Editorial Board of the journal from all papers published in volume 12 . 